Published in final edited form as:

J Phys Chem B. 2004 October 21; 108(42): 16577-16585.

\title{
How Does an Amide-15N Chemical Shift Tensor Vary in Peptides?
}

\author{
Alan Poon, Jeff Birn, and A. Ramamoorthy ${ }^{*}$ \\ Biophysics Research Division, Department of Chemistry, University of Michigan, Ann Arbor, \\ Michigan 48109-1055
}

\begin{abstract}
This study addresses a void in the existing literature on the amide- ${ }^{15} \mathrm{~N}$ chemical shift anisotropy (CSA) tensor of peptides: a systematic investigation of how the tensor varies in different peptides. Amide- ${ }^{15} \mathrm{~N}$ CSA tensors for several dipeptides are obtained using quantum chemical calculations, as well as for a series of model Ala-X and X-Ala sequences in both $\alpha$-helical and $\beta$-sheet conformations (where $\mathrm{X}$ is one of the naturally occurring amino acids). The calculated values show a significant variation in both isolated and extended peptide structures. Hydrogen bonding at both the carbonyl group and the $\mathrm{N}-\mathrm{H}$ bond of the peptide plane is shown to affect the principal values of the tensor. Calculations on model peptides indicate that the amide- $-{ }^{15} \mathrm{~N}$ CSA tensor is dependent on atoms located within a distance of five bonds. Consequently, the tensor of a given peptide residue is unaffected by residues other than those adjacent to it, which implies that the amide- ${ }^{15} \mathrm{~N}$ CSA tensor should be considered in the context of tripeptide sequences. This further suggests that the amide- ${ }^{15} \mathrm{~N}$ CSA tensor of the second residue of a given tripeptide sequence may be extrapolated to the same sequence in any other polypeptide or protein, given the same backbone conformation and intermolecular environment. These conclusions will facilitate future NMR structural studies of proteins.
\end{abstract}

\section{Introduction}

One of the overriding goals of modern biochemistry is to understand protein function through the study of structure and dynamics. Such an understanding will undoubtedly lend fresh insights to pharmaceutical, biochemical, and other related fields of interest. Endeavors to characterize and predict protein structures better therefore assume a high priority. An indispensable tool in such endeavors is NMR spectroscopy, which affords detailed information about the structure, dynamics, and energetics of a molecule. An understanding and utilization of proteins begins with the study of structure, for which NMR spectroscopy is one of the most widely used biophysical techniques.

There is a 3D anisotropy of electronic shielding around NMR-active nuclei, which are often averaged out to yield an isotropic shift in NMR experiments. This chemical shift anisotropy (CSA) is largely dependent on the surrounding chemical environment and thus serves as an excellent indicator of local protein structure. The CSA around a spin nucleus can be represented mathematically as a tensor, which includes the chemical shielding values along the three principal axes of the tensor and the orientation of these principal axes in the molecular frame. The chemical environment around a given nucleus can be deduced by its effects on the principal values and orientation of a CSA tensor; conversely, trends in CSA tensor information can lead to generalizations about the effect of the chemical environment on CSA.

\footnotetext{
*To whom correspondence should be addressed. E-mail: ramamoor@umich.edu. Phone: (734) 647-6572. Fax: (734) 615-3790.

Supporting Information Available: Amide- ${ }^{15} \mathrm{~N}$ tensors and backbone dihedral angles. This material is available free of charge via the Internet at http://pubs.acs.org.
} 
The amide- ${ }^{15} \mathrm{~N}$ nucleus is of particular interest, because it lies within the peptide bonds of proteins and is thus a main component of the protein structure. ${ }^{1,2}$ Amide- ${ }^{15} \mathrm{~N}$ CSA tensors have been used in the structural studies of proteins in the solid state $e^{3-5}$ and liquid crystalline state, $1,2,6$ and in relaxation studies of globular proteins in solution. ${ }^{7-12}$ For example, structural studies of membrane-associated peptides in lipid bilayers using PISEMA experiments ${ }^{13-15}$ and globular proteins using TROSY experiments ${ }^{16}$ highly depend on the availability CSA tensors. Despite their importance, very few well-characterized amide- ${ }^{15} \mathrm{~N}$ CSA tensors have been reported in the literature. Even though solid-state NMR experiments on a single crystal have been shown to provide accurate CSA tensor parameters, only one complete amide- ${ }^{15} \mathrm{~N}$ CSA tensor has so far been reported using this method.${ }^{17} \mathrm{By}$ contrast, several solid-state NMR studies on powder samples have provided accurate principal values, and a few studies also reported the orientation of the tensor in the molecular frame. ${ }^{18-31}$ Solution NMR studies have also been performed to measure amide- ${ }^{15}$ N CSA tensors from proteins. ${ }^{32-38}$ However, it is unfeasible to determine the amide- ${ }^{15} \mathrm{~N}$ CSA tensor experimentally for every system of interest. Characterization of the variation of the amide- ${ }^{15} \mathrm{~N} \mathrm{CSA}$ tensor in peptides is therefore impracticable using experimental techniques alone.

To overcome this difficulty, quantum chemical calculations on model peptides have been used to calculate CSA tensors. ${ }^{39-46}$ Recent reports have demonstrated good agreement between calculated and experimental results for CSA tensors. $31,42,43$ Despite such progress in the field of quantum chemical calculations, the amide- ${ }^{15} \mathrm{~N}$ CSA tensor remains a relatively unexplored subject. Previous studies have focused primarily on the general effects of a number of variables on the CSA tensor. They have shown that the tensor is highly affected by the backbone torsion angles directly adjacent to the amide- ${ }^{15} \mathrm{~N}$ nucleus, and that the shielding effects from neighboring peptide residues are additive. ${ }^{39,40}$ These conclusions indicate that the amide- ${ }^{15} \mathrm{~N}$ CSA tensor is highly contingent on the local geometry of the peptide. Research also shows, almost unanimously, that the principal values of the tensor are affected by intermolecular interactions and hydrogen bonding at the amide site. ${ }^{31,41-44} \mathrm{~A}$ recent study of the orientation of the amide- ${ }^{15} \mathrm{~N}$ CSA tensor predicts that the tensor orientation may change with varying peptide residues. ${ }^{43}$ Another study has shown that the inclusion of partial charges in the extended structures of peptides improves calculated CSA values.

Although the sensitivity of the tensor to such variables has been well established, a quantitative study of how the tensor varies within different peptide residues is, to our knowledge, so far absent from the literature. The motivation of the present research is to systematically investigate the variation of the amide- ${ }^{15} \mathrm{~N}$ CSA tensor in different dipeptides using quantum chemical calculations. It is our intention that these results will expand upon the existing research into the broader context of structural determination, and serve as a starting point for understanding the variation of the tensor in membrane-associated as well as other biologically interesting proteins.

\section{Methods}

This study investigates the amide- ${ }^{15} \mathrm{~N}$ CSA tensors of eight dipeptides based on experimentally determined crystal structures. The X-ray crystallographic coordinates of seven dipeptides and the neutron diffraction coordinates of Gly-Gly were gleaned from the literature. ${ }^{47}$ Empirical parameters were chosen as the basis for the tensor calculations to reflect their structures more accurately than with the use of model peptides, which have been the basis of previous studies. The position of hydrogen atoms in structures were energy minimized according to PM3 parameters ${ }^{48}$ using CAChe Worksystem Pro 5.0 software. ${ }^{49}$ Calculations were performed using the gauge-including atomic orbital (GIAO) computational method of Gaussian 98 software $^{50}$ on PCs of varying clock speeds (800-1700 MHz, 256-768 MB RAM). In 
accordance with convention, shielding constants are converted to chemical shift values relative to liquid ammonia ( $\delta=244.6 \mathrm{ppm}$ at $25 \mathrm{C}$ ) by the following equation:

$\delta_{i i}($ chemical shift $)=\delta_{\text {ammonia }}-\sigma_{i i}$ (shielding constant)

The three principal shift values correspond to the three principal shielding axes ( $\sigma_{33} \geq \sigma_{22} \geq$ $\left.\sigma_{11}\right)$ of the CSA tensor, such that $\delta_{11} \geq \delta_{22} \geq \delta_{33}$, where $\delta_{\text {iso }}$ is the average of these values. The tensor span $\Omega$ is defined as $\left|\delta_{11}-\delta_{33}\right|$, the difference between the largest and smallest principal shift values. Tensor orientations were calculated from the Gaussian 98 output using the rotational matrix equation reported in a recent publication. ${ }^{43}$ The orientation is related to the molecular frame by three Euler angles $\alpha, \beta$, and $\gamma$, where $\alpha$ represents the angle between the most shielded axis $\delta_{33}$ and the projection of the $\mathrm{N}-\mathrm{H}$ bond onto the $\delta_{33}-\delta_{22}$ plane; $\beta$, the angle between the least shielded axis $\delta_{11}$ and the $\mathrm{N}-\mathrm{H}$ bond; and $\gamma$, the angle between $\delta_{11}$ and its projection onto the peptide plane. Thus, the CSA tensor can be completely described by six parameters: three principal shift values $\left(\delta_{11}, \delta_{22}, \delta_{33}\right)$ and three orientation angles $(\alpha, \beta, \gamma)$. We have also calculated ${ }^{15} \mathrm{~N}$ shielding parameters from the principal shift values, where

$$
\begin{gathered}
\delta_{\mathrm{dev}}=\delta_{22}-\delta_{33} \\
\Gamma=\left(\delta_{11}-\delta_{\mathrm{iso}}\right)\left(1-\frac{\eta^{2}}{3}\right)^{1 / 2} \quad \eta=\frac{\delta_{\mathrm{dev}}}{\delta_{11}}
\end{gathered}
$$

Calculations performed on the eight dipeptides were chosen to demonstrate the effect of select variables on the amide- ${ }^{15} \mathrm{~N}$ tensor as the dipeptide residues change. The calculations used a $6-311++\mathrm{G}(2 \mathrm{~d}, 2 \mathrm{p})$ basis set on the following core amide group of atoms:<smiles>CC(=O)NC(C)(C)C</smiles>

A 4-31G basis set was used on the remainder of each structure. This locally dense basis set approach has been shown to be effective in previous studies. ${ }^{51}$ Two structural variables were then investigated: (1) intermolecular interactions and (2) the effect of $\mathrm{N}$-formyl and C-amide protecting groups. Following these, calculations were performed on models of the 40 possible alanine dipeptides (Ala-X and X-Ala, where $\mathrm{X}$ is one of the 20 naturally occurring amino acids). The alanine dipeptides were modeled in both helical and sheet conformations for a total of 80 calculations. In these model peptides, the effects of three additional variables on the amide- ${ }^{15} \mathrm{~N}$ CSA tensor are considered: (3) side chain, (4) adjacent residue, and (5) secondary conformation of the peptide backbone.

\section{Results}

\section{Effect of Intermolecular Interactions}

To address the effect of intermolecular interactions on the variation of the amide- ${ }^{15} \mathrm{~N}$ CSA tensor among dipeptides, the structure of each peptide molecule was considered within its crystal structure. A calculation of an entire crystal structure would be intractable, involving too many atoms to finish in a reasonable amount of time. Instead, the full hydrogen-bonding network of each peptide of interest was selected to within $3 \AA$ and simplified as partners based on formaldehyde, formamide, ammonia, and related structures. The positions of hydrogen atoms were then energy minimized, and a locally dense basis set was applied to the amide core and its direct hydrogen bonding partners. Figure 1 shows, as an example for all eight dipeptides, the structure of a single Ala-Gly molecule next to the structure incorporating the extended molecular network. The data for the extended crystal structures are given in Table 1. 
Not surprisingly, the inclusion of the extended molecular structure significantly affects the principal values of the tensor. The magnitudes of the shift changes range from as little as 1 $\mathrm{ppm}$ to as much as $38 \mathrm{ppm}$, though they are more commonly located around $10 \mathrm{ppm}$. The shift changes in Gly-Gly have by far the largest magnitude, around $35 \mathrm{ppm}$ for the most and least shielded axes $\delta_{33}$ and $\delta_{11}$, and around $12 \mathrm{ppm}$ for $\delta_{22}$. This is likely a result of the simplicity of the glycine residues, which have only hydrogen atoms as their side chains: the lack of steric hindrance from any side chains may make the amide- $-{ }^{15} \mathrm{~N}$ nucleus more sensitive to nearby molecules. This explanation agrees with the magnitude of shift changes in Ala-Gly, another dipeptide consisting of simple residues, which are also relatively large (around 9-13 ppm).

When the magnitudes of shift changes are compared with the directions of the changes, a couple of notable trends emerge. First, the shift value of the most shielded axis, $\delta_{33}$, increases in all cases, which suggests that the basic effect of hydrogen bonding is to deshield the amide- ${ }^{15} \mathrm{~N}$ nucleus. Second, the direction of change in $\delta_{22}$ is dependent on whether the carbonyl oxygen in the same peptide plane as the amide- ${ }^{15} \mathrm{~N}$ nucleus participates in hydrogen bonding. In structures where the carbonyl oxygen participates in hydrogen bonding ( $\beta$-Ala-His, Ala-Met, Ala-Ser, Gly-Gly, and Gly-Asn), the value of $\delta_{22}$ decreases; in structures where it does not (Ala-Gly, Glu-Gly, and Gly-Phe), the value of $\delta_{22}$ increases. This may occur because hydrogen bonding at the carbonyl oxygen favors the following resonance structure, in which the $\pi$ bonding increases the shielding perpendicular to the peptide plane and hence decreases the value of $\delta_{22}$ :<smiles>CC([O-])=[NH+]C(C)(C)C</smiles>

The magnitude of these changes is usually within $10 \mathrm{ppm}$, though the shift change is relatively small in Ala-Met and Gly-Phe (1 ppm). The change in Ala-Met is small because, among those extended structures that have a hydrogen-bonding partner at the carbonyl oxygen, the bond distance in Ala-Met $(2.7 \AA$ ) is much longer than in the others (around 1.8-2.1 $\AA$ ). The change in Gly-Phe is small because, although there is technically no hydrogen-bonding partner at the carbonyl oxygen in Gly-Phe, there is an ammonia molecule located within $3 \AA$ of the oxygen atom. The ammonia molecule is not oriented properly with respect to the oxygen to form a hydrogen bond, but it is close enough for the nitrogen and oxygen atoms to affect each other. Therefore, even though there is no hydrogen bond at the carbonyl oxygen, which increases the value of $\delta_{22}$, there is an intermolecular interaction, which apparently causes a small increase in $\delta_{22}$. These two cases thus represent intermediate kinds of hydrogen bonding at the carbonyl oxygen, which explains why their shift changes in $\delta_{22}$ are marginal.

The data reported here show that intermolecular interactions also affect the CSA tensor orientations. The direction of change of $\gamma$, in particular, is inversely correlated with the direction change of the shift of the least shielded principal axis, $\delta_{11}$, in each dipeptide. In structures where the value of $\gamma$ increases, the shift value of $\delta_{11}$ decreases; in structures where $\gamma$ decreases, the value of $\delta_{11}$ increases. Because $\gamma$ measures how far the least shielded principal shift axis $\delta_{11}$ deviates from the peptide plane (defined by the amide $\mathrm{N}-\mathrm{H}$ bond), these data suggest that shielding around the amide- ${ }^{15} \mathrm{~N}$ nucleus increases out of the peptide plane. Thus, changes in $\delta_{11}$ can be explained by changes in the $\gamma$ angle. The sole exception to this trend is Ala-Ser: with the inclusion of the extended molecular structure, the values of both $\gamma$ and $\delta_{11}$ increase. This is probably because the serine side chain includes an alcohol functional group near the amide group. The oxygen and hydrogen atoms of this group are both located around $2.8 \AA$ from the amide- ${ }^{15} \mathrm{~N}$ nucleus, so that the $\delta_{11}$ shift axis is deshielded by interactions with the side-chain 
alcohol group. Such an intramolecular interaction would reconcile the tensor data for Ala-Ser with the trend that changes in $\gamma$ are linked to changes in $\delta_{11}$.

In all, these results demonstrate that intermolecular interactions at the carbonyl group, as well as the amide $\mathrm{N}-\mathrm{H}$ bond, of the peptide plane have a significant effect on the amide- ${ }^{15} \mathrm{~N}$ CSA tensor. Furthermore, such interactions are highly dependent on the geometry of the structures and imply an intimate relationship between the principal shift values and the tensor orientation.

\section{Effect of Formyl and Amide Protecting Groups}

To investigate whether more distant residues of a polypeptide affect a given amide- ${ }^{15} \mathrm{~N}$ CSA tensor, calculations were performed on the isolated dipeptide molecules with model $\mathrm{N}$-formyl and $\mathrm{C}$-amide protecting groups added to the $\mathrm{N}$ - and $\mathrm{C}$-terminal ends, respectively. The protecting groups are intended to simulate the effect of continuing residues on both sides of the dipeptide. Hydrogen atom positions were optimized following the addition of the model protecting groups. The data for the $\mathrm{N}$-formyl and $\mathrm{C}$-amide compounds are given in Supporting Information.

The addition of the $\mathrm{N}$-formyl group shifts the isotropic chemical shift downfield by about 1 ppm or less (except for Ala-Ser), but the addition of C-amide has the opposite effect (except for Gly-Asn). Consequently, very little change in the span of the chemical shift tensor was found in most cases. Similarly, the addition of either formyl or amide protecting groups to most dipeptides produces small changes in the principal tensor shift values, around $5 \mathrm{ppm}$ or less. However, large changes are found in Gly and Ala-Ser. In the case of Gly-Gly, the change is greater (as much as $12 \mathrm{ppm}$ for $\delta_{22}$ ), probably because the simplicity of the glycine side chains makes the amide- ${ }^{15} \mathrm{~N}$ nucleus more sensitive to adjacent residues. With the addition of both $\mathrm{N}$-formyl and $\mathrm{C}$-amide protecting groups, the changes in the principal values are approximately the sum of the effects due to the $\mathrm{N}$-formyl and $\mathrm{C}$-amide groups considered separately. The additive effect of residues on the principal shift values of the amide- ${ }^{15} \mathrm{~N} \mathrm{CSA}$ tensor confirms the conclusion of one recent study. ${ }^{52}$ In the case of Ala-Ser, the changes in $\delta_{11}, \delta_{22}$, and $\delta_{33}$ are about 18,6 , and $12 \mathrm{ppm}$, respectively, but the change in the span is only about $6 \mathrm{ppm}$. These large changes may be attributed to the close proximity of an alcohol functional group in the serine side chain and the $\mathrm{N}$-formyl group. This could particularly deshield the principal components $\left(\delta_{11}\right.$ and $\left.\delta_{33}\right)$ that lie in the peptide plane.

The data for $\beta$-Ala-His are particularly significant. Because the alanine residue is in the $\beta$ form, the $\mathrm{N}$-terminus is one bond more distant from the amide- ${ }^{15} \mathrm{~N}$ nucleus than in the other dipeptides. The addition of an $\mathrm{N}$-formyl protecting group changes the terminal $\mathrm{N}$ nucleus from tetrahedral to planar geometry. Thus, where in other dipeptides this change occurs at a distance of three bonds from the amide- ${ }^{15} \mathrm{~N}$ nucleus, in $\beta$-Ala-His it occurs at a distance of four bonds. The data for $\mathrm{N}$-formyl $\beta$-Ala-His show changes in the principal values of around 1-2 ppm. This indicates that the amide- ${ }^{15} \mathrm{~N}$ nucleus is affected by atoms at a distance of at least four bonds, a conclusion that will be supported with further evidence in this paper.

The magnitudes of the changes in the tensor orientation angles, on the other hand, are insignificant compared to changes in the shift values. For any given angle, the addition of either or both $\mathrm{N}$-formyl and $\mathrm{C}$-amide protecting groups rarely causes a change of more than $2^{\circ}$. As with the principal shift values, the change is slightly greater for the Gly-Gly orientation angles, up to $4^{\circ}$, as a result of the sensitivity of the glycine amide- ${ }^{15} \mathrm{~N}$ nucleus. For the rest of the dipeptides, the tensor orientation is unaffected.

These results, taken together, suggest that the effect of distant residues on the amide- ${ }^{15} \mathrm{~N}$ CSA tensor values is minimal. Orientation is insensitive to the $\mathrm{N}$-formyl and $\mathrm{C}$-amide protecting groups, and changes in the principal shift values are small $(\leq 5 \mathrm{ppm})$ when compared to the 
variation brought about by intermolecular interactions $(\leq 15 \mathrm{ppm})$ and the variation among different dipeptides (as much as $30 \mathrm{ppm}$ ). This further suggests that shielding around a given amide- ${ }^{15} \mathrm{~N}$ nucleus is affected by atoms only as far as the adjacent residues. This observation motivates the investigation of model peptides, which will be addressed in the following three sections.

\section{Effect of Side Chains}

The variation of the amide- ${ }^{15} \mathrm{NCSA}$ tensors belonging to different residues was surveyed using model $\mathrm{N}$-formyl Ala-X amide dipeptides in both $\alpha$-helical and $\beta$-sheet conformations. All of the structures were derived arbitrarily from the optimized $\mathrm{N}$-formyl Ala-Ser amide structure: the side group of the serine residue was altered to 1 of the 20 naturally occurring amino acid residues, the positions of the hydrogen atoms and the entire side chain of $X$ were energy minimized, and the backbone dihedral angles of both residues were adjusted to the appropriate values. These steps were taken to control the bond lengths and angles of the model structures such that the only variables among them are the backbone conformation and the side chain on the $\mathrm{X}$ residue. The goal of using these structures is not prediction since Ala-Ser is the only empirically accurate structure; rather, it is to identify trends associated with the effect of side chains on the amide- ${ }^{15} \mathrm{~N}$ CSA tensor (and, in the following sections, the effects of an adjacent residue and the backbone conformation). The amide- ${ }^{15} \mathrm{~N}$ tensor values for the $\mathrm{X}$ residues are given in Supporting Information, and Figure 2a-d graphically represents their ${ }^{15} \mathrm{~N}$ shielding parameters. For convenience, a statistical summary of the data set for each tensor value is presented in Table 2. These statistics should be used only as a rough estimator of trends, however, because they do not consider the changes in individual structures.

Each set of principal shift values of the tensor among the Ala-X structures has a large standard deviation and a wide range, both of which indicate high variation. This, in turn, suggests that the identity of the residue to which the amide- ${ }^{15} \mathrm{~N}$ nucleus belongs has a large effect on the tensor values. A few cases stand out. The principal shift values in Ala-Pro are outliers in both conformations. This is because of the unique structure of proline. The proline ring structure is particularly disruptive to $\alpha$-helical conformations, for which reason proline is often called a "helix-breaking" residue. This characteristic explains the unusually high shift values for the Ala-Pro helix. Ala-Gly and Ala-Ser have principal shift values lower than the rest of the data, though for different reasons. The amide- ${ }^{15} \mathrm{~N}$ CSA tensor of glycine has unusual shifts because glycine is the only residue with a hydrogen atom as a side chain. The data for Ala-Ser are slightly low because it is the only structure based on empirical data as a result of the procedure chosen to construct the model peptides. Its backbone structure is thus more energy minimized, which increases the shielding around the amide $-{ }^{15} \mathrm{~N}$ nucleus and lowers its principal shift values. Thus, for purposes of determining protein structures, cases in which an amide- ${ }^{15} \mathrm{~N}$ nucleus belongs to either a proline or a glycine residue should be considered unique.

There is also variation in the orientations of tensors belonging to different residues, though it is less pronounced than with the principal shift values. The greatest variation occurs with angle $\alpha$, and the least, with angle $\beta$. These data, taken together with the principal shift data, indicate that the residue side chain located two bonds away from the amide- ${ }^{15} \mathrm{~N}$ nucleus does have a significant effect on the CSA tensor values.

\section{Effect of an Adjacent Residue}

In the model X-Ala structures, the amide- ${ }^{15} \mathrm{~N}$ nucleus belongs to the alanine residue, and the preceding residue changes. The same procedure used to construct the Ala-X peptides, was used for the X-Ala peptides such that the only variables among the structures are the backbone conformation and the side chain on the $\mathrm{X}$ residue. In these structures, however, the changing 
side chain is an additonal bond more distant from the amide- ${ }^{15} \mathrm{~N}$ nucleus than in the Ala-X structures.

The amount of variation in the principal shift values for X-Ala structures is less than that reported for Ala-X structures, and depends on the conformation of the peptide. In the helical conformation, the standard deviation of each set of shift values is considerably large, around 3-3.5 ppm; however, in the sheet conformation, the standard deviation is much lower in the $\delta_{33}$ and $\delta_{22}$ values, around $1 \mathrm{ppm}$. This indicates that the side chain of the residue downstream of the amide- ${ }^{15} \mathrm{~N}$ nucleus has a significant effect on the CSA tensor values in the helical conformation but less so in the sheet. The data for Pro-Ala and Gly-Ala confirm this indication. The $\delta_{33}$ and $\delta_{11}$ shift values for the Pro-Ala helix are lower than the rest of the data, presumably because the unique ring structure of proline is still close enough to affect the amide- ${ }^{15} \mathrm{~N}$ nucleus; however, in the sheet conformation, none of the shift values are outliers. Likewise, the values of $\delta_{33}$ and $\delta_{11}$ in the Gly-Ala helix are relatively low and high, respectively; but in the sheet conformation, the same parameters are consistent with the rest of the data. It should also be noted that the data for Ser-Ala are not unusual because its structure is no longer empirically accurate, as it is in Ala-Ser.

The variation in tensor orientation is also substantially less than in the Ala-X structures. As with the principal shift values, the variation of the orientation is less in the sheet conformation than in the helical. The values of angle $\beta$, in particular, are nearly invariable, with standard deviations of $0.2^{\circ}$ in the helical conformation and $0.1^{\circ}$ in the sheet. The values of $\gamma$ become nearly constant in the sheet conformation as well. These data, taken together with the principal shift data, indicate that the adjacent residue side chain, located an extra bond away from the amide- ${ }^{15} \mathrm{~N}$ nucleus in comparison with the side chains in the Ala-X peptides, still has an effect on the principal values of the CSA tensor, though it is marginal, and that the effect is dependent on the backbone conformation. This, in turn, implies a cooperative effect of three variables on the amide- ${ }^{15} \mathrm{~N}$ CSA tensor: the identity of nearby side chains, the distance of those side chains to the amide- ${ }^{15} \mathrm{~N}$ nucleus, and the backbone conformation of the peptide.

\section{Effect of Backbone Conformation}

The data show the backbone conformation to have a substantial effect on the amide- ${ }^{15} \mathrm{~N}$ CSA tensor values. This effect is independent of the identity of $\mathrm{X}$ and whether the dipeptide is Ala$\mathrm{X}$ or X-Ala. Disregarding the data points for Ala-Pro, which has a unique geometry, the $\beta$ sheet conformation raises the values of the least shielded principal axis, $\delta_{11}$, by around $25-30$ ppm and the values of $\delta_{22}$ by around 20-25 ppm compared to the $\alpha$-helical conformation. The values of $\delta_{\text {iso }}$ and $\Omega$ are higher in the $\beta$-sheet conformation by around 15 and $23-25 \mathrm{ppm}$, respectively. The value of angle $\beta$ is also generally higher by $5^{\circ}$ in the $\alpha$-helical conformation.

\section{Comparison to Experimental Data}

The procedure used in the calculations so far-locally dense basis set, optimization of hydrogen atoms, and inclusion of hydrogen bonding fragments - may be evaluated by comparing the Gly-Gly tensor values in both isolated and extended structures with their corresponding experimental values ${ }^{13}$ (data shown in Table 1). For each individual shift component, incorporation of the extended crystal structure in the calculations reduces the mismatch from the experimental values; for the most shielded axis, $\delta_{33}$, the error is reduced substantially, by $15 \mathrm{ppm}$. The isotropic shift, however, still deviates from the experimental by a notable margin. There may be several reasons for this. First, the neutron diffraction structure used in the calculations may differ from the one used in the experimental study. Second, the calculations themselves may include an inadequate portion of the extended molecular crystal. As mentioned above, the Gly-Gly molecule may be particularly sensitive to intermolecular effects because 
of the lack of hindrance from side-chain groups, so the inclusion of additional molecules in the crystal structure might be expected to increase the accuracy of the calculations.

Calculations were also performed on $N$-acetyl-L-valyl-L-leucine (NAVL) and several Glycontaining peptides for which the X-ray crystal structure ${ }^{53,54}$ and amide- ${ }^{15} \mathrm{~N}$ CSA tensor values, measured from solid-state NMR experiments, are well documented. ${ }^{27,30}$ Calculated and experimental results are summarized in Table 3. Reasonable accuracy in the principal values is achieved using the quantum calculation approach, similar to the degree of accuracy achieved by Brender et al. in their calculations of the same compound. ${ }^{43}$ A higher degree of accuracy is achieved for the orientation angles. The angle $(\beta)$ between the least shielded component $\left(\delta_{11}\right)$ and the $\mathrm{N}-\mathrm{H}$ bond found in the range of $16-28^{\circ}$ is in excellent agreement with the reported experimental studies. $25,27,30,43$ The nonzero values obtained for angle $\alpha$ are also in very good agreement with the experimental studies. ${ }^{25,27,30,43}$ Discrepancies between the calculated and experimental shift values can be attributed to one or more possible factors. ${ }^{43}$ There may be differences between the structures used in the crystallographic and experimental studies, an insufficient basis set may have been used in the calculations, or intermolecular interactions may have been improperly included.

More distant charges in the crystal structure arising from $\mathrm{COO}^{-}$and $\mathrm{NH}_{3}{ }^{+}$groups on individual molecules may also be expected to affect a given amide- ${ }^{15} \mathrm{~N}$ CSA tensor. One recent study has examined such effects on the amide- ${ }^{15} \mathrm{~N}$ CSA tensor of Ala-Ala. ${ }^{42}$ The effects of direct hydrogen bonding partners are considered separately and then in conjunction with point charges selected to within a radius of $13 \AA$. The results show the inclusion of point charges to improve the calculated tensor values significantly with respect to experimental data, much beyond the improvement gained by the inclusion of hydrogen bonding fragments alone. This suggests that the absence of such charges in the calculations undertaken in the present research may explain the discrepancies between the calculated and experimental tensor values. To test this, calculations of the amide- ${ }^{15} \mathrm{~N}$ CSA tensor were performed on the Ala-Ala structure provided by the study. The results, taking into consideration the hydrogen bonding partners but not point charges, are given alongside the experimental values in Table 3. It is apparent that a wide discrepancy still exists between the calculated and experimental results. The calculated values are similar to those in the same study that consider hydrogen bonding partners only. However, our calculations on AGG with the inclusion of partial charges for a radius of $10 \AA$ from the amide $-{ }^{15} \mathrm{~N}$ site of the central Gly residue and hydrogen bonding partners did not provide good accord with the experimental data $(60,80$, and $243 \mathrm{ppm}$ from calculations and 53.4, 60.6, and $215 \mathrm{ppm}$ from experiments with an error of $\pm 1.5 \mathrm{ppm}^{30}$ ). Interestingly, considering partial charges alone (i.e., with the exclusion of hydrogen bonding partners) on AGG significantly improved the calculated values (58.5, 67, and $220 \mathrm{ppm})$. This is consistent with the previous theoretical study 42 that also showed that the inclusion of hydrogen bonding partners along with the partial charges on the $\mathrm{N}$ and $\mathrm{C}$ termini of the peptides did not improve the calculated CSA values. Another recent study that included point charges but no hydrogen bonding partners in the calculations showed very good improvement in ${ }^{13} \mathrm{C} \mathrm{CSA}$ tensor values, but for several cases, ${ }^{15} \mathrm{~N}$ CSA tensors did not exactly match the experimental values. ${ }^{31}$ These studies suggest that, with the present level of quantum chemical calculations, there is no unique way to obtain accurate amide- ${ }^{15} \mathrm{~N}$ CSA values. Therefore, there is a need for more theoretical studies that can accurately determinate ${ }^{15} \mathrm{~N}$ CSA tensors of peptides and proteins. While the inclusion of point charges may improve the accuracy of the calculated values, it considerably increases the calculation time. Therefore, it is difficult to carry out calculations including point charges on a sufficient number of peptides to understand the variation of CSA reported in this study.

Although the absolute values of principal components of the ${ }^{15} \mathrm{~N}$ CSA tensor reported in this study are not in good agreement with the experimental values (Table 3), there are several trends 
in the variation of the tensor that do agree with the experimental studies reported in the literature. Larger $\delta_{\text {iso }}$ values calculated for the helical conformation than for the sheet conformation is in good agreement with solution NMR studies of globular proteins. ${ }^{2}$ This is also in good agreement with the prediction from a recent study 46 that a direct hydrogen bonding to the amide- ${ }^{-15} \mathrm{~N}$ deshields the value by $3.7 \mathrm{ppm}$ in a helical conformation whereas it is only $1.2 \mathrm{ppm}$ in sheet conformation. In addition, the lowest isotropic chemical shift value calculated for the Gly residue in both conformations is also in complete agreement with solution NMR studies. ${ }^{2}$ A calculated CSA span of 170.3 ppm for N-formyl Ala- ${ }^{15} \mathrm{~N}$-Gly amide (and 179.5 ppm for N-formyl-Gly-Ala-amide) in a sheet conformation is in good agreement with the average value of $174.2 \pm 4 \mathrm{ppm}$ for all sheet residues in ubiquitin obtained from a solution NMR study 55 and also with a recent solid-state NMR study on glycine-containing peptides that predicted a range of $169-176 \pm 1.5 \mathrm{ppm} .{ }^{30}$ In general, the span of the CSA tensor calculated is in good agreement with the solid-state NMR data as shown in Figure 3. Larger deviations from the axial symmetry of the tensor for glycine in a sheet conformation than in a helical conformation found in the calculated values are also good for solution ${ }^{55}$ and solid-state $\mathrm{NMR}^{30}$ studies. The angles defining the orientation of the tensor are in good agreement with experimental $17,23,25,27,30,35$ and previous theoretical studies. ${ }^{43}$

\section{Discussion}

\section{Five-Bond Radius of Effect}

The data from $\mathrm{N}$-formyl $\beta$-Ala-His suggests that the amide- ${ }^{15} \mathrm{~N}$ CSA tensor is affected by intramolecular atoms at a distance of four bonds away. This hypothesis can be tested more fully by an analysis of the model alanine dipeptides. The model dipeptides are particularly apt for this discussion, because the side chains of the $\mathrm{X}$ residues in the X-Ala structures are one additional bond away from the amide- ${ }^{15} \mathrm{~N}$ nucleus than in the Ala-X structures. This makes the comparison of atoms at different bond distances straightforward. To undertake this analysis, it is not enough to organize the tensor data by side chain alone; the actual atoms of each side chain must be identified. The radius to which the amide- ${ }^{15} \mathrm{~N}$ CSA tensor is affected is most clearly demonstrated by observing the point at which similar kinds of residues show a lack of variation in tensor data - the point at which the amide- ${ }^{15} \mathrm{~N}$ nucleus is unaffected by the side chain. As the X-Ala peptides show, the amount of variation also depends on the backbone conformation, so the variation in each conformation must be considered separately.

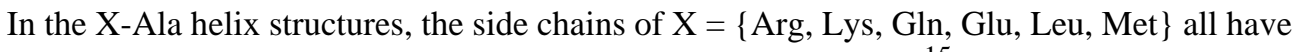
the same kinds of atoms located four bonds away from the amide- ${ }^{15} \mathrm{~N}$ nucleus. Yet, there is still variation in the amide- ${ }^{15} \mathrm{~N}$ CSA tensors of these structures. This suggests that the amide $-{ }^{15} \mathrm{~N}$ nucleus is affected by atoms more than four bonds away. For $X=\{\mathrm{Arg}$, Lys $\}$, however, the side chains on $\mathrm{X}$ are identical up to a distance of four bonds in the Ala-X structures and five bonds in X-Ala. The principal shift values for the Ala-Arg helix differ from those for the Ala-Lys helix by around $1 \mathrm{ppm}$ and up to $3.5^{\circ}$ in orientation; however, in the X-Ala helix structures, the tensors match almost exactly. In other words, helix structures identical up to four bonds away from the amide- ${ }^{15} \mathrm{~N}$ nucleus yield different tensors, but structures identical up to a distance of five bonds yield the same tensor. Atoms five bonds away in the Ala-Arg and Ala-Lys structures must be the source of the difference between their amide- ${ }^{15} \mathrm{~N} \mathrm{CSA}$ tensors, but in the Arg-Ala and Lys-Ala structures, those atoms are six bonds away and cause no variation. This clearly shows that the amide- ${ }^{15} \mathrm{~N}$ CSA tensor of a residue in the helical conformation is affected by atoms at a distance of five bonds.

In the Ala-X sheet structures, as in the helical structures, the group of residues $X=\{\operatorname{Arg}$, Lys, Gln, Glu, Leu, Met $\}$ produce varying tensors. However, the same residues in the X-Ala sheet structures produce much more similar tensors. The subgroup $X=\{$ Arg, Lys $\}$, with side chains identical to a distance of at least four bonds, also produces nearly the same tensor information 
in both the Ala-X sheet and X-Ala sheet structures. These data show that the sheet structures identical up to a distance of three bonds produce different tensors, whereas those identical at four bonds or more from the amide- ${ }^{15} \mathrm{~N}$ nucleus produce approximately the same tensor. This suggests that the amide- ${ }^{15} \mathrm{~N}$ CSA tensor in sheet peptides is affected by atoms at a distance of only four atoms. The data for the model X-Ala peptides support this conclusion, since there is very little variation in the tensor data from the sheet structures.

The same logic used for the group of residues $X=\{$ Arg, Lys, Gln, Glu, Leu, Met $\}$ can be applied to other similar groups such as $X=\{$ Asn, Asp, His, Phe, Trp, Tyr $\}$ and $X=\{$ Ile, Val $\}$. An analysis of these groups leads to the same conclusions given above: in the helical conformation, the amide- ${ }^{15} \mathrm{~N}$ CSA tensor is affected by atoms up to a distance of five bonds, whereas in the sheet, the radius of effect is four bonds. There is thus a relationship between the sensitivity of the amide- ${ }^{15} \mathrm{~N}$ nucleus and the conformation of the peptide. However, because the backbone conformation of a peptide is not always known or easy to determine, a blanket choice of five bonds should be taken as the effective radius.

\section{Reevaluation of Empirical Tensor Values}

Presently, with the knowledge gained from the model peptides, it becomes possible to reexamine the variation in the eight empirical structures originally considered in this paper. An analysis of the model alanine dipeptides has suggested that the amide- ${ }^{15} \mathrm{~N}$ CSA tensor is affected by intramolecular atoms within a distance of five bonds. The relatively high principal shift values of $\beta$-Ala-His may thus be explained as a result of the $\beta$ form of the alanine residue. The $\mathrm{N}$-terminus in $\beta$-alanine is four bonds away from the amide- ${ }^{15} \mathrm{~N}$ nucleus, whereas in every other structure, that distance is three bonds. Because this change is within the effective distance of the amide- $-{ }^{15} \mathrm{~N}$ nucleus, it should have a substantial effect on the tensor values. To test this, model $\alpha$-Ala-His was constructed on the basis of the empirical $\beta$-Ala-His structure. The calculated tensor values are given alongside the original values for $\beta$-Ala-His in Table 4 . The data show that changing the alanine residue from the $\beta$ to $\alpha$ form, effectively restoring the $\mathrm{N}$ terminus to within three bonds of the amide- ${ }^{15} \mathrm{~N}$ nucleus, considerably lowers the values of $\delta_{22}, \delta_{11}, \delta_{\text {iso }}$, and $\Omega$, such that they are more similar to the rest of the data. The value of the most shielded component, $\delta_{33}$, rose unexpectedly by $6 \mathrm{ppm}$; however, this effect does not diminish the general effect felt by the other tensor components. The elevation of the $\beta$-Ala-His principal shift values can therefore be attributed to the extra distance of the $\mathrm{N}$-terminus relative to the $\alpha$-residue structures, and lends further evidence to an amide- ${ }^{15} \mathrm{~N}$ effective distance of five bonds.

The model dipeptides also reveal that the backbone conformation has a substantial effect on the amide- ${ }^{15} \mathrm{~N}$ CSA tensor values. Accordingly, the observed variation among the tensors of the original dipeptides may be a consequence of different backbone conformations. To test this, the backbone dihedral angles of each empirical structure were measured. (These measurements are given in Supporting Information.) The conformations of Gly-Gly and AlaMet are found to be very similar to each other, within several degrees. It follows that, all other things being equal, their tensor values in the molecular calculations should also be similar. Comparing their tensor values in Table 1, the principal shift values are within the same vicinity, differing by around $7-12 \mathrm{ppm}\left(17 \mathrm{ppm}\right.$ in $\left.\delta_{33}\right)$. The tensor orientations in each molecule differ by around $10-15^{\circ}$. These differences are not extreme, but are nonetheless significant: they must be the consequence of other differences between the Ala-Met and Gly-Gly structures. Thus, whereas the similar backbone conformations of the two structures yield tensor values seemingly close to each other, the comparison is obscured by variables such as different bond lengths, angles, and nearby atoms. Such variables extend beyond the scope of this paper and deserve attention in future studies. 


\section{Potential for Extrapolation}

The ability to extrapolate known tensors to those of undetermined structures is essential in structural studies of proteins. The $\mathrm{N}$-formyl and $\mathrm{C}$-amide peptide data presented in this paper suggest that distant residues in a polypeptide - those beyond the $i_{-1}$ th and $i_{+1}$ th residues - have a minimal effect on the amide- ${ }^{15} \mathrm{~N}$ CSA tensor. This observation agrees with the effective radius determined in the last section, which explains why the $\mathrm{N}$-formyl and $\mathrm{C}$-amide protecting groups have an observable effect even if that effect is small. The tripeptide should thus be considered to be the basic structural unit associated with the amide- ${ }^{15} \mathrm{~N}$ CSA tensor. This study also indicates that intermolecular interactions and the backbone conformation have significant effects on the amide- ${ }^{15} \mathrm{~N}$ CSA tensor. The tensor of a given amide- ${ }^{15} \mathrm{~N}$ nucleus can therefore be extrapolated to the same tripeptide sequence in any other protein, provided that the peptide conformations and intermolecular environments (crystal packing in the solid state) are equivalent.

\section{Conclusions}

This study was motivated by the ambition to characterize the variation of the amide- ${ }^{15} \mathrm{~N}$ CSA tensor in different dipeptides, as a prelude to more complicated protein structural studies. Quantum chemical calculations performed on a variety of empirical and model dipeptide structures reveal at least three main sources of the variation: atoms located within an effective radius from the amide- ${ }^{15} \mathrm{~N}$ nucleus; the backbone conformation of the peptide; and intermolecular interactions. Hydrogen bonding at both the carbonyl group and $\mathrm{N}-\mathrm{H}$ bond of the peptide plane was found to affect the value of the CSA tensor significantly. The amide- ${ }^{15} \mathrm{~N}$ nucleus was also found to be affected by intramolecular atoms within a distance of five bonds, as well as the dihedral angles of the peptide backbone. The effective radius of five bonds provides a convenient cutoff point for ${ }^{15} \mathrm{~N}$ NMR studies, and further implies that it is necessary to consider only the $i_{-1}$ th through the $i_{+1}$ th residues in determining the amide- ${ }^{15} \mathrm{~N}$ CSA tensor belonging to the $i$ th residue of a polypeptide. The amide- ${ }^{15} \mathrm{~N} \mathrm{CSA}$ tensor of a given tripeptide sequence can therefore be extrapolated to the same sequence in any other polypeptide, provided that the backbone conformations and intermolecular environment are equivalent. Although the magnitudes of individual principal elements did not match the experimental values well, the spans of tensors are in good agreement with the reported experimental data. It is hoped that the results and conclusions presented in this paper will encourage further studies on the amide- ${ }^{15} \mathrm{~N}$ CSA tensor related to structural determination.

\section{Acknowledgment}

We thank Yuchun Mao for his participation in the initial stages of this research. This research was supported by funds from the National Science Foundation (CAREER development award to A. R) and the NIH (AI054515-01A1 to A.R). A.P. was supported by the Moses Gomberg summer research fellowship from the Department of Chemistry.

\section{References and Notes}

1. Wishart DS, Case DA. Methods Enzymol 2001;338:3-34. [PubMed: 11460554]

2. Zhang H, Neal S, Wishart DS. J. Biomol. NMR 2003;25:173-195. [PubMed: 12652131]

3. Lee D-K, Santos JS, Ramamoorthy A. J. Phys. Chem. B 1999;103:8383.

4. Opella SJ, Stewart PL, Valentine KG. Q. Rev. Biophys 1987;19:7. [PubMed: 3306759]Ramamoorthy, A.; Marassi, FM.; Opella, SJ. Dynamics and the Problem of Recognition in Biological Macromolecules. Plenum Press; New York: 1996. Kovacs FA, Denny JK, Song Z, Quine JR, Cross TA. J. Mol. Biol 2000;295:117-125. [PubMed: 10623512]Wildman KAH, Lee D-K, Ramamoorthy A. Biochemistry 2003;42:6545. [PubMed: 12767238]

5. Marassi FM, Opella SJ. J. Magn. Reson 2000;144:150-155. [PubMed: 10783285]Wang J, Denny J, Tian C, Kim S, Mo Y, Kovacs F, Song Z, Nishimura K, Gan Z, Fu R, Quine JR, Cross TA. J. Magn. Reson 2000;144:162-167. [PubMed: 10783287]Cross, TA.; Kim, S.; Wang, J.; Quine, JR. From 
Topology to High-Resolution Structures; Proceedings of the Workshop on The Future of Solid State NMR in Biology; Leiden, The Netherlands. 2001; Dordrecht, The Netherlands: Kluwer Academic

Publishers; 2001.p. 55-70.Kovacs FA, Cross TA. Biophys. J 1997;73:2511-2517. [PubMed: 9370444]

6. Ulmer TS, Ramirez BE, Delaglio F, Bax A. J. Am. Chem. Soc 2003;125:9179-9191. [PubMed: 15369375]

7. Fushman D, Cowburn D. J. Am. Chem. Soc 1998;120:7109-7110.

8. Fushman D, Tjandra N, Cowburn D. J. Am. Chem. Soc 1999;121:8577-8582.

9. Fushman D, Cowburn D. J. Biomol. NMR 2003;13:139-147. [PubMed: 10070755]

10. Fushman D, Cowburn D. Methods Enzylmol 2001;331:109-126.

11. Lipsitz RS, Tjandra N. J. Magn. Reson 2003;164:171-176. [PubMed: 12932470]

12. Wang TZ, Cai S, Zuiderweg ERP. J. Am. Chem. Soc 2003;125:8639-8643. [PubMed: 12848571]

13. Wu CH, Ramamoorthy A, Opella SJ. J. Magn. Reson., Ser. A 1994;109:270.Ramamoorthy A, Opella SJ. Solid-State NMR Spectrosc 1995;4:387-392.

14. Ramamoorthy A, Wu CH, Opella SJ. J. Magn. Reson 1999;140:131-140. [PubMed: 10479555]

15. Ramamoorthy A, Wei Y, Lee DK. Annu. Rep. NMR Spectrosc 2004;52:1-52.

16. Wuthrich K. Nat. Struct. Biol 2001;8:923-925. [PubMed: 11685234]

17. Harbison GS, Jelinski LW, Stark RE, Torchia DA, Herzfeld J, Griffin RG. J. Magn. Reson 1984;60:79-82.

18. Hartzell CJ, Whitfield M, Oas TG, Drobny GP. J. Am. Chem. Soc 1987;109:5966-5969.

19. Valentine KG, Rockwell AL, Gierasch LM, Opella SJ. J. Magn. Reson 1987;73:519-523.

20. Roberts JE, Harbison GS, Munowitz MG, Herzfeld J, Griffin RG. J. Am. Chem. Soc 1987;109:41634169.

21. Hiyama Y, Niu CH, Silverton JV, Bavoso A, Torchia DA. J. Am. Chem. Soc 1988;110:2378-2383.

22. Wang C, Teng Q, Cross TA. Biophys. J 1992;61:1550-1556.

23. Wu CH, Ramamoorthy A, Opella SJ. J. Am. Chem. Soc 1995;117:6148-6149.

24. Lee D-K, Ramamoorthy A. J. Magn. Reson 1998;133:204-206. [PubMed: 9654488]

25. Lee D-K, Wittebort RJ, Ramamoorthy A. J. Am. Chem. Soc 1998;120:8868-8874.

26. Lee D-K, Santos JS, Ramamoorthy A. Chem. Phys. Lett 1999;309:209-214.Wei Y, Lee D-K, Ramamoorthy A. Chem. Phys. Lett 2000;324:24.

27. Lee D-K, Wei Y, Ramamoorthy A. J. Phys. Chem. B 2001;105:4752-4762.

28. Wei Y, McDermott A, Lee D-K, Ramamoorthy A. J. Magn. Reson 2002;158:23-35. [PubMed: 12419668]Fukutani A, Naito A, Tuzi S, Saito H. J. Mol. Struct 2002;602-603:491-503.

29. Shekar SC, Lee D-K, Ramamoorthy A, Wittebort R. J. Magn. Reson 2002;155:257-262. [PubMed: 12036337]

30. Chekmenev EY, Zhang Q, Waddell KW, Mashuta MS, Wittebort RJ. J. Am. Chem. Soc 2004;126:379-384. [PubMed: 14709105]

31. Strohmeier M, Grant DM. J. Am. Chem. Soc 2003;126:966-977. [PubMed: 14733574]

32. Tjandra N, Szabo A, Bax A. J. Am. Chem. Soc 1996;118:6986-6991.

33. Fushman D, Tjandra N, Cowburn D. J. Am. Chem. Soc 1998;120:10947-10952.

34. Fushman D, Tjandra N, Cowburn D. J. Am. Chem. Soc 1998;120:10947-10952.

35. Boyd J, Redfield C. J. Am. Chem. Soc 1998;121:9692-9693.

36. Boyd J, Redfield C. J. Am. Chem. Soc 1999;121:7441-7442.

37. Kroenke CD, Rance M, Palmer AG III. J. Am. Chem. Soc 1999;121:10119-10125.

38. Canet D, Barthe P, Mutzenhardt P, Roumestand C. J. Am. Chem. Soc 2001;123:4.

39. de Dios AC, Pearson JG, Oldfield E. Science 1993;260:1491-1496. [PubMed: 8502992]

40. Le H, Oldfield E. J. Phys. Chem 1996;100:16423-16428.

41. Walling AE, Pargas RE, de Dios AC. J. Phys. Chem. A 1997;101:7299-7303.

42. Scheurer C, Skrynnikov NR, Lienin SF, Straus SK, Brüschweiler R, Ernst RR. J. Am. Chem. Soc 1999;121:4242-4251. 
43. Brender JR, Taylor DM, Ramamoorthy A. J. Am. Chem. Soc 2001;123:914-922. [PubMed: 11456625]

44. Xu XP, Case DA. J. Biomol. NMR 2001;21:321-333. [PubMed: 11824752]

45. Sun H, Sander LK, Oldfield E. J. Am. Chem. Soc 2002;124:5486-5495. [PubMed: 11996591]

46. Xu XP, Case DA. Biopolymers 2002;65:408-423. [PubMed: 12434429]

47. Pasternak RA, Katz L, Corey RB. Acta Crystallogr 1954;7:225-236.Koch MHJ, Germain G. Acta Crystallogr., Sect. B 1970;26:410-417.Stenkamp RE, Jensen LH. Acta Crystallogr., Sect. B 1974;30:1541-1545.Marsh RE, Ramakumar S, Venkatesan K. Acta Crystallogr., Sect. B 1976;32:66-70.Itoh H, Yamane T, Ashida T. Acta Crystallogr., Sect. B 1977;33:2959-2961.Kvick A, Al-Karaghouli AR, Koetzle TF. Acta Crystallogr., Sect. B 1977;33:3796-3801.Jones PG, Falvello L, Kennard O. Acta Crystallogr., Sect. B 1978;34:1939-1942.Eggleston DS, Valente EJ, Hodgson DJ. Acta Crystallogr., Sect. B 1981;37:1430-1433.

48. Stewart JJP. J. Comput. Chem 1989;10:209.Stewart JJP. J. Comput. Chem 1989;10:221.

49. CaCHE Worksystem Pro Version 5.0. Fujitsu Ltd.; 2001. 1989-2000 Oxford Molecular Ltd

50. Frisch, MJ.; Trucks, GW.; Schlegel, HB.; Scuseria, GE.; Robb, MA.; Cheeseman, JR.; Zakrzewski, VG.; Montgomery, JA., Jr.; Stratmann, RE.; Burant, JC.; Dapprich, S.; Millam, JM.; Daniels, AD.; Kudin, KN.; Strain, MC.; Farkas, O.; Tomasi, J.; Barone, V.; Cossi, M.; Cammi, R.; Mennucci, B.; Pomelli, C.; Adamo, C.; Clifford, S.; Ochterski, J.; Petersson, GA.; Ayala, PY.; Cui, Q.; Morokuma, K.; Malick, DK.; Rabuck, AD.; Raghavachari, K.; Foresman, JB.; Cioslowski, J.; Ortiz, JV.; Stefanov, BB.; Liu, G.; Liashenko, A.; Piskorz, P.; Komaromi, I.; Gomperts, R.; Martin, RL.; Fox, DJ.; Keith, T.; Al-Laham, MA.; Peng, CY.; Nanayakkara, A.; Gonzalez, C.; Challacombe, M.; Gill, PMW.; Johnson, BG.; Chen, W.; Wong, MW.; Andres, JL.; Head-Gordon, M.; Replogle, ES.; Pople, JA. Gaussian 98. Gaussian, Inc.; Pittsburgh, PA: 1998.

51. Chestnut DB, Rusiloski BE, Moore KD, Egolf DA. J. Comput. Chem 1993;14:1364-1375.

52. Luman NR, King MP, Augspurger JD. J. Comput. Chem 2001;22:366-372.

53. Carroll PJ, Stewart PL, Opella SJ. Acta Crystallogr., Sect C 1990;46:243-246.

54. Srikrishnan N, Winiewicz N, Parthasarathy R. Int. J. Pept. Protein Res 1982;19:103-113. [PubMed: 7118387]Lalitha V, Subramanian E, Bordner J. Int. J. Pept. Protein Res 1984;24:437-441. [PubMed: 6519914]Lalitha V, Subramanian E, Bordner J. Indian J. Pure Appl. Phys 1985;23:506-508.Lalitha V, Murali R, Subramnian E. Int. J. Pept. Protein Res 1986;27:472-477.Subramnian E, Sahayamary JJ. Int. J. Pept. Protein Res 1989;34:211-214. [PubMed: 2599758]Lalitha V, Subramanian E, Parthasarathy R. Int. J. Pept. Protein Res 1986;27:223-228. [PubMed: 3710690]Carson WM, Hackert ML. Acta Crystallogr., Sect. B 1978;34:1275-1280.

55. Cornilescu G, Bax A. J. Am. Chem. Soc 2000;122:10143-10154. 

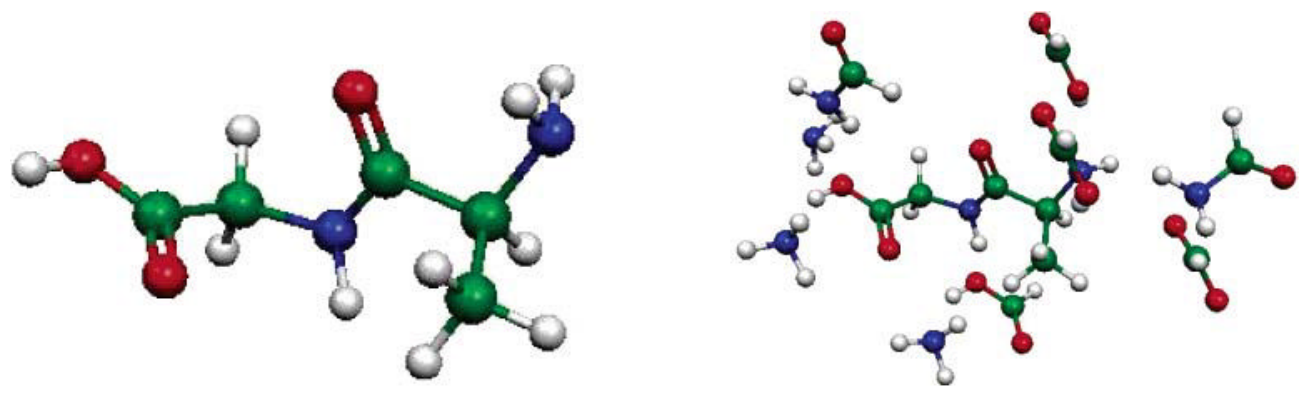

Figure 1.

Isolated and extended crystal structures for Ala-Gly. 

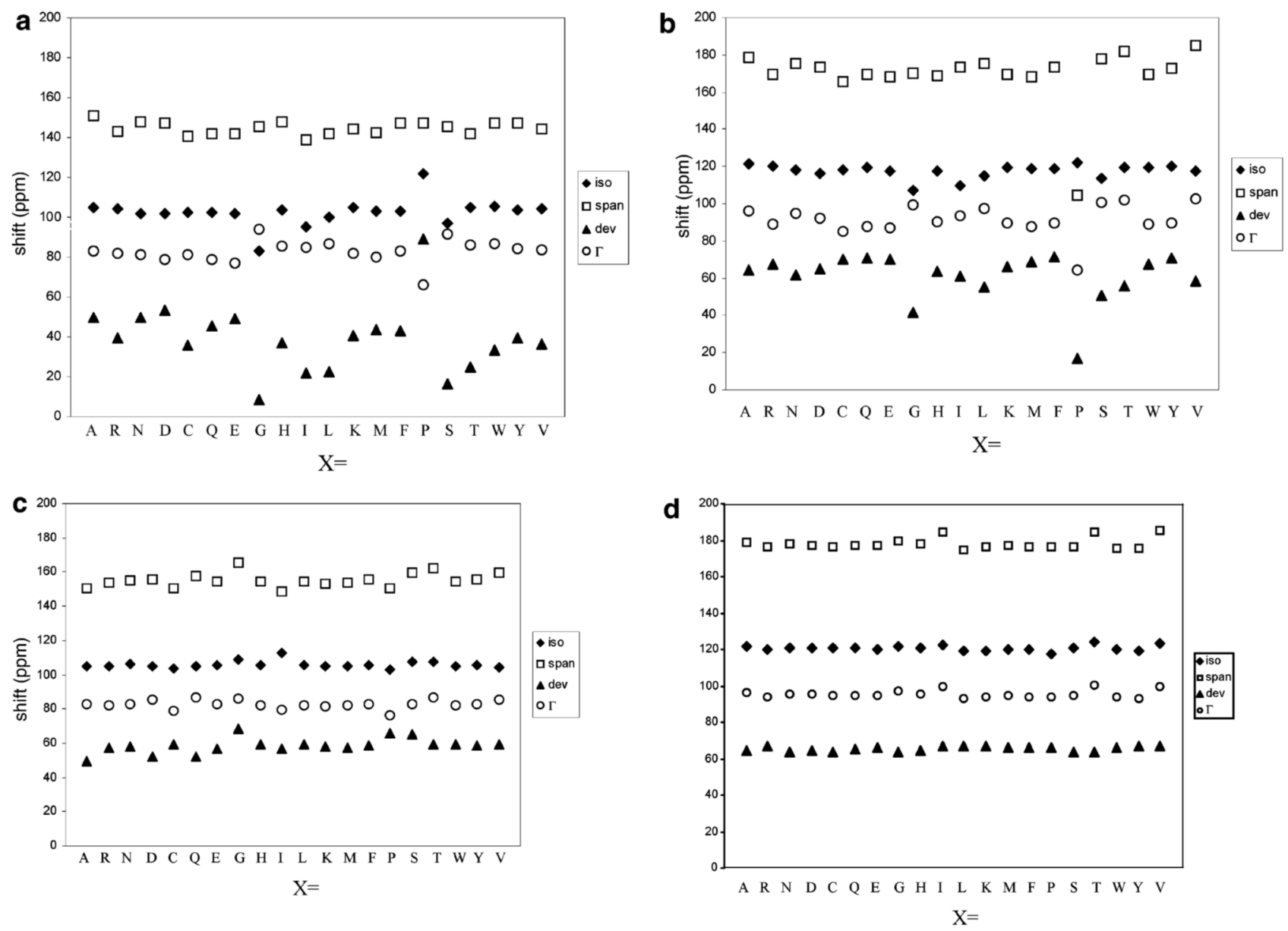

Figure 2.

(a) ${ }^{15} \mathrm{~N}$ shielding parameters for model Ala-X helix structures. (b) ${ }^{15} \mathrm{~N}$ shielding parameters for model Ala-X sheet structures. (c) ${ }^{15} \mathrm{~N}$ shielding parameters for model X-Ala helix structures. (d) ${ }^{15} \mathrm{~N}$ shielding parameters for model X-Ala sheet structures. 


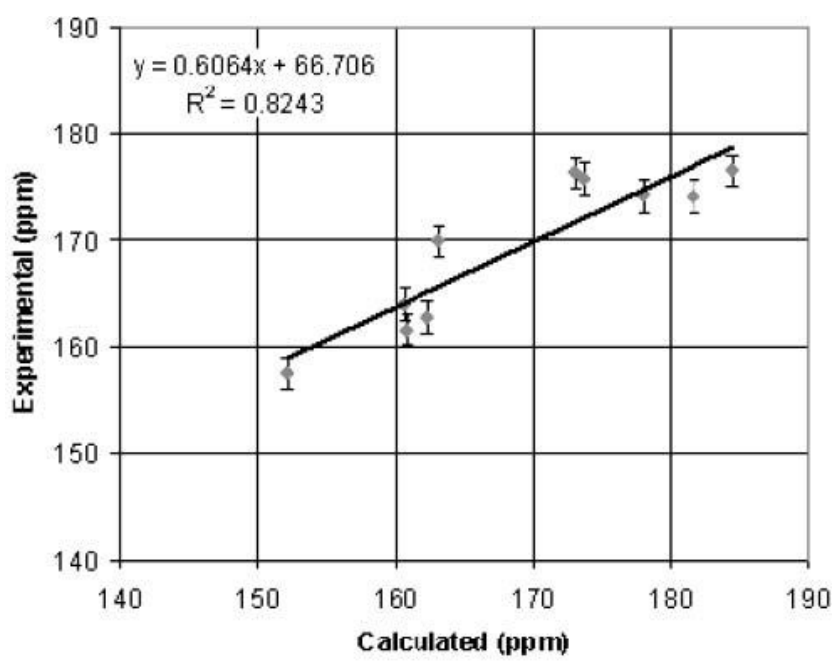

Figure 3.

Comparison of experimental and calculated chemical shift spans for peptides given in Table 3. 


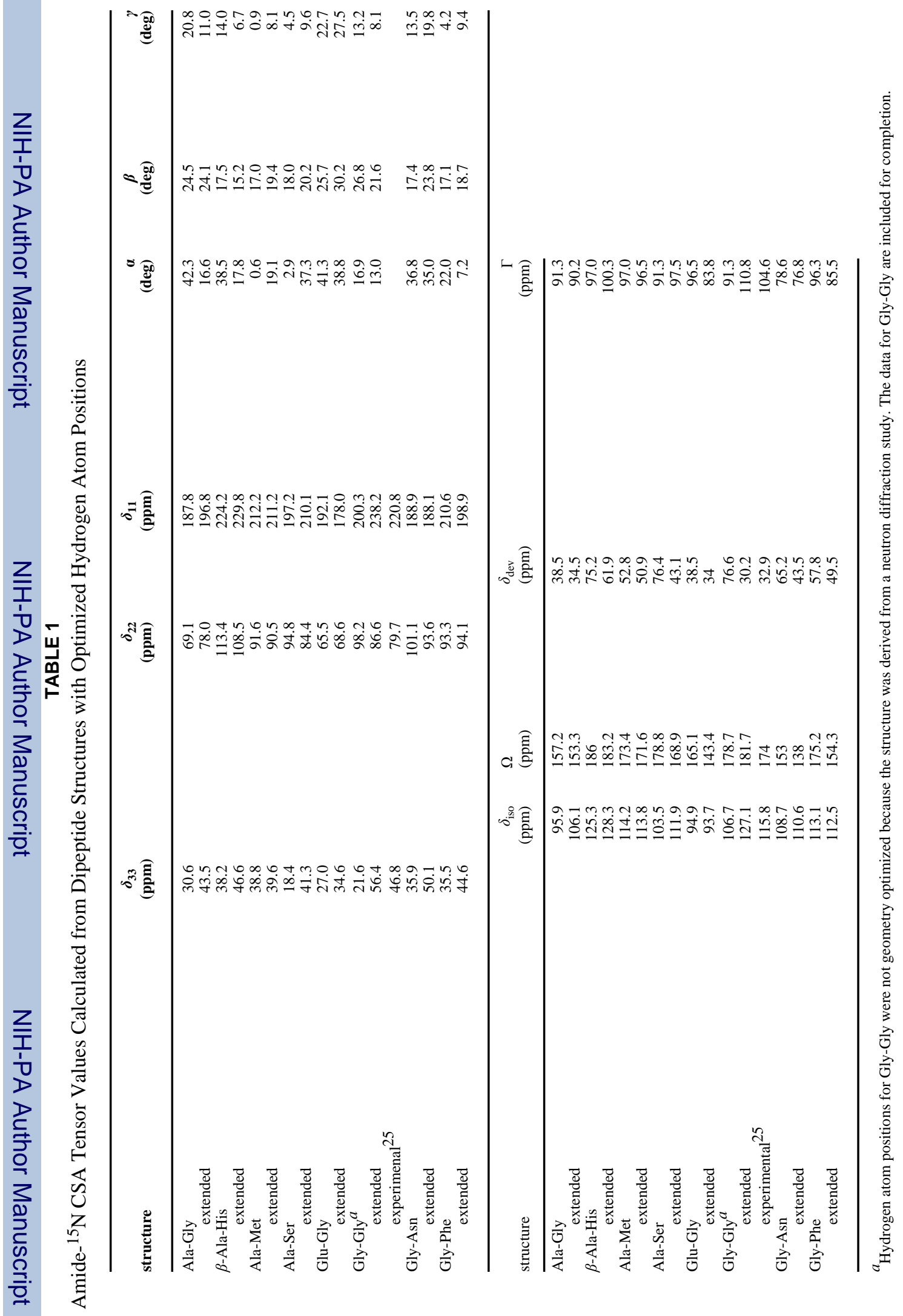




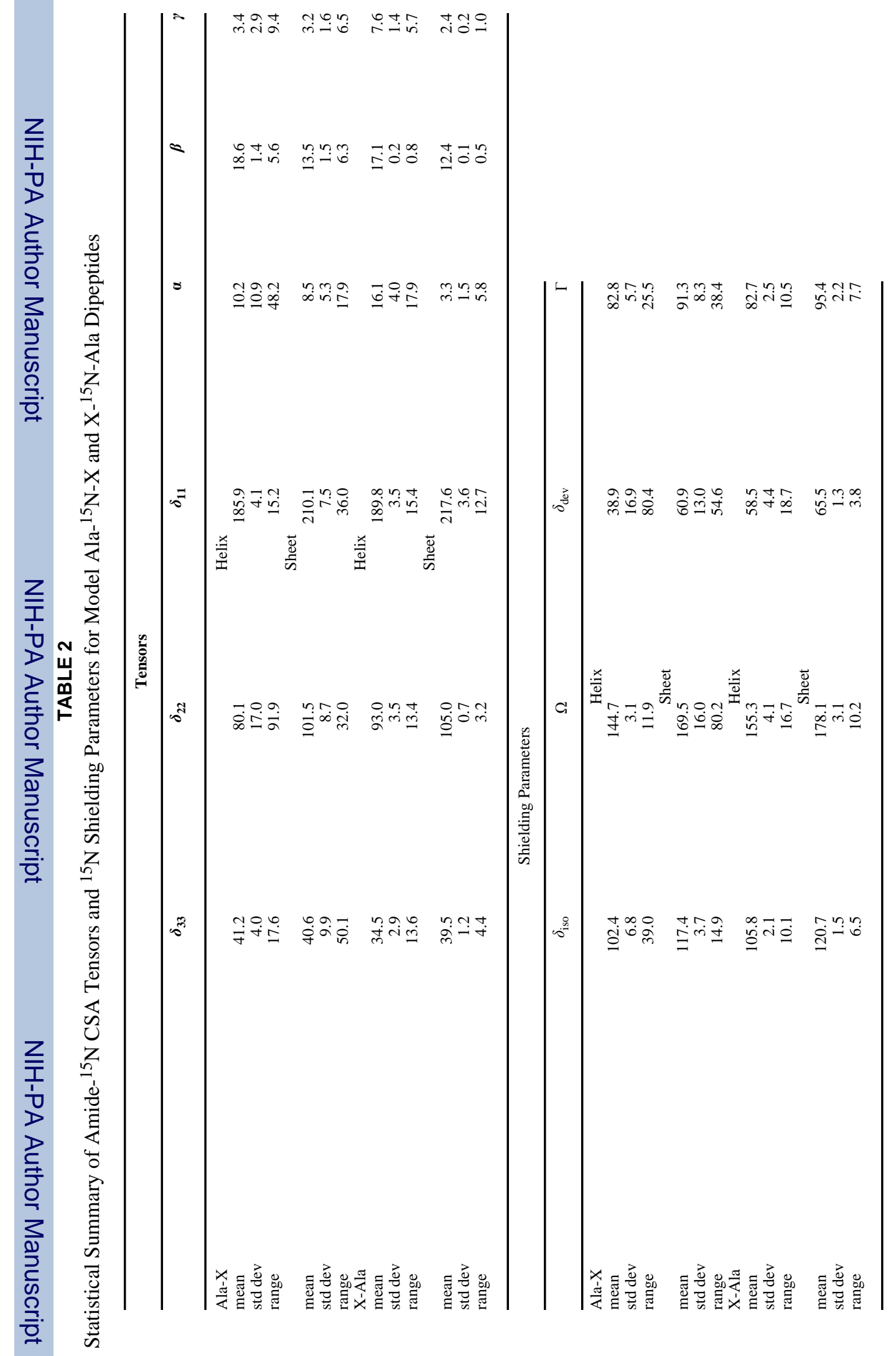




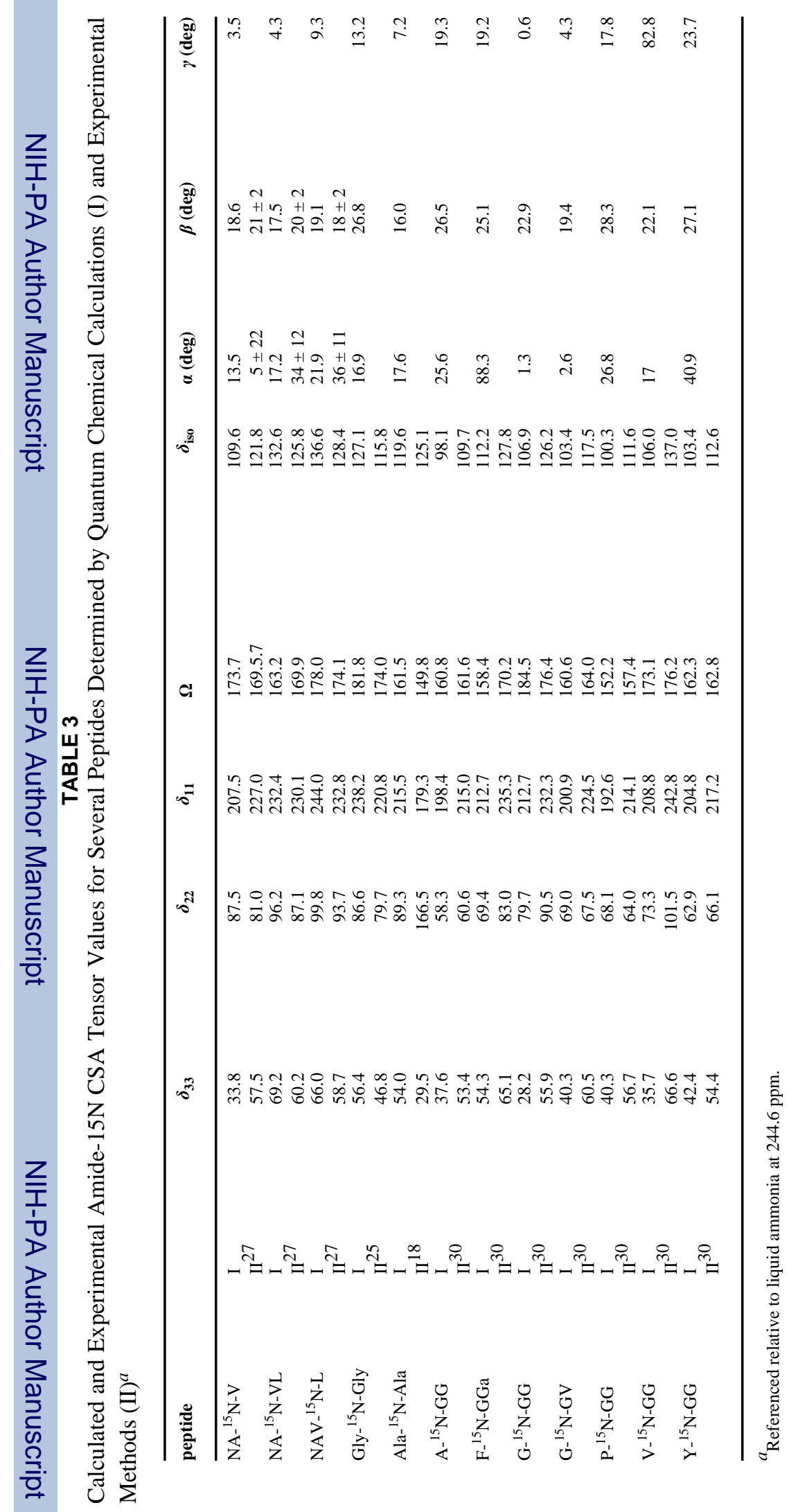




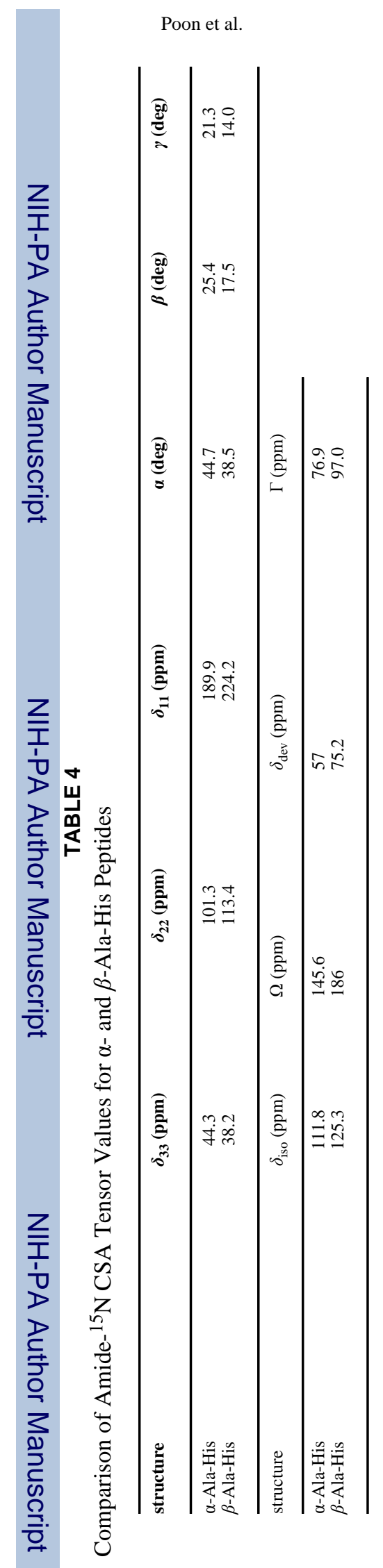

Page 20 